\title{
"As mulheres são más": pessoa, gênero e doença no sul de Moçambique*
}

\author{
Luiz Henrique Passador*
}

\begin{abstract}
Resumo
Partindo de um caso de doença e morte atribuídas à feitiçaria, o artigo analisa as articulações entre pessoa, gênero e doença que operam no Sul de Moçambique, onde as mulheres são tradicionalmente temidas e acusadas de produzirem malefícios através de feitiços.
\end{abstract}

Palavras-chave: Moçambique, Gênero, Parentesco, Feitiçaria, Doença.

\footnotetext{
" Recebido para publicação em setembro de 2009, aceito em agosto de 2010. Texto resultante de pesquisa para o doutorado (PPGAS-Unicamp) sobre a "tradição" e o universo das doenças no Sul de Moçambique, atentando para a experiência local com a epidemia de HIV/Aids. O trabalho de campo transcorreu no Distrito de Homoíne, Província de Inhambane, entre junho de 2007 e fevereiro de 2008, financiado pela CAPES através do Programa de Estágio de Doutorando no Exterior. O trabalho foi inicialmente orientado pelo Dr. Omar Ribeiro Thomaz e atualmente é orientado pela Dra. Mariza Corrêa (PPGASUnicamp) e co-orientado pela Dra. Teresa Cruz e Silva (CEA-UEM).

** Doutorando em Antropologia Social, PPGAS-Unicamp. lhpassador@gmail.com
}

cadernos pagu (35), julho-dezembro de 2010:177-.210. 
"As mulheres são más"

"Women are Evil":

Personhood, Gender and Illness in Mozambique

\begin{abstract}
Taking a case of illness and death attributed to sorcery, the article examines the connections between personhood, gender and disease in Southern Mozambique, where women are traditionally feared and accused of producing evil through spells.
\end{abstract}

Key Words: Mozambique, Gender, Kinship, Witchcraft, Illness. 
O título deste artigo reproduz uma frase que ouvi em Homoíne, distrito ao Sul de Moçambique. Ela pareceu-me reveladora de uma configuração de gênero que impõe experiências específicas para as mulheres naquele universo social. Para explicá-la e contextualizá-la, remeto-me à descrição de um fato que lá observei em 2007.

Em outubro faleceu José ${ }^{1}$, jovem de 27 anos, natural de Homoíne, professor de inglês numa escola da vila-sede do distrito e casado com Dalva, uma professora de 23 anos, natural de Gaza. A doença que o acometeu fê-lo definhar em menos de um mês, desencadeando uma série de acusações de feitiçaria envolvendo familiares, vizinhos e certas mulheres, e estabelecendo conexões com outras mortes no seio de seu grupo familiar e numa rede ampliada de relações de amizade entre uma parcela de jovens influentes na vila-sede de Homoíne.

O caso envolve diversos elementos que procurarei resumir para torná-lo minimamente inteligível. José era o segundo filho do segundo casamento de seu pai, um curandeiro ${ }^{2}$ polígamo - este vivia com sua segunda esposa, mãe de José, e a terceira, tendo se separado da primeira, que à época vivia no Distrito de Morrumbene, de onde o pai é natural e onde tem suas machambas. ${ }^{3}$ José casara-se com Dalva em 2006, sem registro civil e sem completar o lobolo ${ }^{4}$ - apenas a apresentação à família da esposa fora formalizada. Foram morar numa casa que José construiu longe da residência paterna. Ele era muito hábil em

1 Todos os nomes de pessoas empregados no texto são fictícios.

2 Os termos curandeiro e curandeirismo são usados em língua portuguesa pelos habitantes de Homoíne e se referem aos médicos e à medicina tradicionais. $\mathrm{O}$ termo para curandeiro em língua local (citsua) é nyanga.

3 Machamba é o termo local que denomina as plantações.

4 Lobolo é o processo tradicional de aliança matrimonial no Sul de Moçambique (ver Bagnol, 2006 e Junod, 2003). Também se emprega o termo para se referir à cerimônia específica que celebra a aliança. O lobolo é tradicionalmente reconhecido como casamento, embora existam formas civis de casamento definidos por lei. 
"As mulheres são más"

estabelecer amizades vantajosas, inclusive com os raros brancos estrangeiros que chegam à vila. Ambicioso, comentava-se não ser muito confiável no que diz respeito a bens alheios, mesmo os de seus familiares. Estava associado a um grupo de jovens influentes na vila, que se organizava em torno da Associação de Futebol distrital, presidida por um dos líderes tradicionais do distrito.

No início de 2007, José e Dalva tiveram seu primeiro e único filho, que faleceu subitamente em abril, acometido por uma doença cujo diagnóstico era cercado de silêncios e meias palavras. Sua irmã mais velha, por parte de pai e mãe, também falecera em 2005 de doença semelhante. Os sintomas eram vômitos, febre constante, dores no corpo, dificuldade para ingerir alimentos sólidos, feridas pelo corpo e na boca, confusão mental $e$ definhamento até a morte. Outros cinco familiares do núcleo de Morrumbene já haviam falecido num período de dois anos, todos com os mesmos sintomas e doença.

Durante o período da enfermidade, José evitava comer qualquer alimento preparado ou oferecido por seus familiares, inclusive sua esposa. Só se alimentava com água de coco e alimentos que conseguia ingerir, trazidos e ministrados por seu melhor amigo - a quem classificava como primo. Nas visitas que fiz a ele, pedia-me que levasse iogurte industrializado, vendido nas lojas. Chegou a ser internado no Centro de Saúde de Homoíne com diagnóstico de malária ${ }^{5}$, mas rapidamente sua família chegou a um diagnóstico de "doença tradicional" provocada por feitiço, retirando-o do hospital e levando-o para casa, onde inicialmente se submeteu a tratamento com um curandeiro indicado pelo pai. Após idas e vindas ao hospital e a vários curandeiros, José faleceu na casa do último curandeiro consultado. Este só teve tempo para

\footnotetext{
5 José já havia contraído malária pouco antes, o que faz pensar que enfrentava uma recidiva. Meses antes, também contraíra uma doença respiratória que não soube informar o diagnóstico, cujo principal sintoma era tosse prolongada.
} 
fazer um diagnóstico parcial do mal através do tihlolo ${ }^{6}$, achando indícios de que o malefício partira de alguém pertencente ao grupo familiar.

Sua morte produziu consternação na vila e desencadeou rumores em torno da autoria do feitiço. O pai, já suspeito de ter provocado as doenças e mortes anteriores no seio da família, passou a ser acusado inclusive pelos filhos. $\mathrm{Na}$ vila, os comentários eram de que "todos sabem que foi o pai" quem provocara a doença e a morte de José. O diagnóstico parcial do último curandeiro só fez acirrar os rumores. A mãe de José também foi envolvida como suposta co-autora, pois não demonstrara tristeza durante o funeral, nem pranteara a morte do filho publicamente - mesma atitude do pai.

Enquanto o caso permanecia inconcluso, a família se reuniu com o pai em Morrumbene na semana seguinte ao funeral. Ele já sabia que era apontado como principal suspeito. Suspeitavam que estivesse matando membros de sua família para obter benefícios através do uso de feitiços, e José teria sido apenas a última vítima. Tido como curandeiro "verdadeiro" porque herdara por descendência poderes de seus antepassados curandeiros, o pai teria também comprado espíritos de outros curandeiros para se tornar mais poderoso, garantir ascensão nas estruturas administrativas e partidárias e manter a alta produtividade de suas machambas. Para continuar a usufruir desses poderes, precisaria matar familiares, que seriam perdas irrisórias para ele diante dos ganhos que supostamente obteria. Além disso, José e sua irmã desafiaram o pai e romperam com seu pátrio poder tradicional, fundado num sistema de descendência agnática e residência patrilocal. A filha decidira sair da casa paterna sem antes se casar, indo morar em Morrumbene. José saíra dos arredores da casa do

6 Tihlolo é o processo divinatório utilizado por curandeiros para interpretarem as causas de um malefício. Também é conhecido como cuxa-cuxa, termo cunhado pelos colonos portugueses. 
"As mulheres são más"

pai para instalar sua residência em outra área. Assim, ambos tornaram-se autônomos em relação ao pai.

José era um sujeito "moderno", por assim dizer. Garantia seu sustento sem ter machambas, estava inserido num mercado de trabalho formal, saíra das estruturas que o submeteriam à órbita paterna e estava em processo de tornar-se um "homem grande" na vila por seus méritos extra-tradicionais e conquistados individualmente dentro de uma rede de amizades privilegiadas. Sua casa nova, com luz elétrica e localizada numa boa vizinhança, era a objetivação dessa situação privilegiada e de independência. Falava-se que a morte de José e de seu filho no mesmo ano foram causadas pela inveja e ira paterna, como represálias ao seu sucesso individual $e$ insubordinação ao pai. Mas dentro do universo "tradicional"7, José também estava em processo de realizar-se como "homem grande". Casara-se com uma esposa jovem, dedicada, trabalhadora e fértil, faltando-lhe apenas os filhos para iniciar seu próprio núcleo de descendência e depois alargá-lo com as alianças matrimoniais que esses perpetrariam.

Durante o período da doença de José, e antes que as acusações endereçadas ao pai e à mãe ganhassem força $e$ consenso, uma série de especulações remetia a causa de sua doença para outros elementos normalmente associados à produção de feitiços e malefícios: os vizinhos e, principalmente, certas categorias de mulheres.

Primeiramente especulou-se sobre o vizinho que vendera o terreno para José construir sua casa. Este vendera sua propriedade apenas por pressão dos filhos. Quando construía sua moradia, José encontrou indícios de um feitiço enterrados no terreno e suspeitou que fosse obra do vizinho descontente com a venda. Segundo essa versão, José teria também cometido um erro fatal: não convidou o vizinho para a festa de inauguração da casa. Isso constituiu uma ruptura com os protocolos que estabelecem

7 Utilizo os termos tradição e modernidade entre aspas por referir-me aos usos êmicos que os habitantes de Homoíne fazem dessas categorias. 
boas relações com a vizinhança. Por esquecimento ou atitude deliberada de um sujeito individualista e pouco atento aos imperativos do universo "tradicional" (do qual desdenhava com freqüência), o certo é que José criara uma situação de tensão com seu vizinho e isso fundamentava os rumores que se seguiram.

Outras versões atribuíam a doença a um universo de "doenças tradicionais" associadas a certos tabus. Uma jovem, filha de curandeira, disse-me suspeitar que José sofria de xivenze, doença que acomete aqueles que, após a morte de um familiar, mantêm relações sexuais ou se apropriam dos bens do morto antes que seja feita a kutchinga. ${ }^{8}$ Segundo ela, talvez José desrespeitara a abstinência sexual devida após a morte do filho, ou então ingerira carne de algum animal doméstico pertencente a alguém recém falecido e que não havia sido previamente purificado.

Um dos amigos de José também aventou hipóteses relacionadas a tabus sexuais e a determinadas mulheres. A primeira era de que talvez José mantivera relações sexuais com alguma viúva não submetida à kutchinga, repetindo a suspeita em torno da xivenze. Outra hipótese era que talvez José mantivera relações sexuais com alguma mulher que abortara e não fora submetida a ritos de purificação. Por fim, suspeitava que Dalva fosse "mulher de dono", cujo "dono" seria um espírito. Viúvas e "mulheres de espírito" estão definidas por um princípio semelhante: têm "dono", ou seja, estão em relação de aliança matrimonial com um homem (ainda que espírito de um morto) $e$

8 Kutchinga é o ritual de purificação de pessoas e bens associados em vida a um sujeito recém falecido. Seus bens só podem ser acessados após a purificação, assim como viúvas e viúvos precisam ser purificados para poderem manter relações sexuais com outros parceiros. Os demais familiares também devem manter abstinência sexual e não utilizar os bens que pertenceram ao falecido até a purificação se completar. Tradicionalmente, a kutchinga também envolve relações sexuais da viúva com seu cunhado. A noção básica é que o esperma "lava" as impurezas da mulher. Quando o cunhado se nega a fazê-lo, escolhe-se outro homem da família ou ainda contrata-se um homem de fora do núcleo familiar. 
"As mulheres são más"

seu acesso por parte de outro homem exige permissão dos "donos", através de cerimônias "tradicionais" - para as viúvas, são necessários a kutchinga e o respeito ao prazo de um ano para que possam deitar-se com outro homem. O rapaz via maior plausibilidade na terceira hipótese, pois dois primos seus tiveram doenças semelhantes à de José após se casarem com "mulheres de espíritos", perderam filhos de pouca idade e eles próprios quase morreram.

No dia seguinte ao funeral fiz uma visita de condolências à família, já sabendo do consenso que se construíra entre os familiares e habitantes da vila acerca da culpabilidade paterna pela morte de José. Ao chegar, encontrei Dalva na companhia de sua mãe e de outras mulheres da família de José (sua cunhada e as esposas do pai). O pai do falecido estava sentado a uma mesa para receber as visitas e sentei-me junto a ele. Eu queria saber sua versão para a morte do filho e arrisquei lhe perguntar. Ele então respondeu que foram "coisas de tradição" que vitimaram José. Argumentou que tudo fizera para salvar o filho, mas nada fora suficiente. Arrisquei novamente e perguntei-lhe qual a causa mais específica nos termos "tradicionais", ou quem havia feito aquilo. Ele respondeu que José "meteu-se com uma puta"9 quando Dalva estava viajando. Ao retornar à casa, caiu doente até morrer. Em tom de cumplicidade, virou-se para mim e complementou em voz baixa: "nós homens estamos mal nas mãos das mulheres, porque as mulheres são más". E repetiu enfaticamente: "as mulheres são más!".

Meses depois encontrei Francisco, irmão de José por parte de pai e mãe, que vive e trabalha em Maputo. Ele mudara-se para lá alegando ter maiores oportunidades de trabalho na capital, mas também um distanciamento do universo "tradicional" e seus perigos. Francisco contou-me que o último curandeiro consultado chegara a um diagnóstico aceito pela família: a seqüência de

9 Referindo-se a mulheres que têm vários parceiros sexuais, não sendo necessariamente profissionais do sexo. 
mortes na família se devia ao fato de o pai ter-se casado com uma "mulher de espírito" (a mãe de José) e ter se recusado a pagar o boi que seu "dono" exigia para permitir o casamento. Assim, as mortes sucessivas no núcleo de descendência de seu pai se deviam à vingança desse espírito. A família o condenava por permitir que o não pagamento da dívida espiritual colocasse todos em risco. Sua esposa, a fonte dos malefícios todos, trazia consigo a vingança de seu "dono" espiritual ao seio familiar.

Essas versões sobre as causas do mal que vitimara José ganhavam plausibilidade porque todas lançavam mão de um consenso socialmente disponível no Sul de Moçambique. Qual seja, que há um universo de malefícios e feitiços atribuídos às mulheres, que revertem em prejuízos, doenças e mortes entre seus pares. Em Homoíne ouvi que a maioria dos feiticeiros $e$ curandeiros é de mulheres, o que as associa a poderes espirituais $e$ malefícios que afligem tanto homens, quanto mulheres. As mulheres são consensualmente vistas como detentoras de um certo tipo de poder e perpetradoras de um certo tipo de violência relacionada a forças espirituais ou a impurezas. Isso as submete a um regime de constante desconfiança e violência, concebida nesses termos como uma forma de contra-violência. É esse aspecto de uma realidade que articula pessoa, gênero e doenças que analiso a seguir.

\section{Tradição}

O universo das "doenças tradicionais" em Homoíne está intimamente relacionado à construção da pessoa e à estruturação das relações de gênero. Para compreendê-lo, contudo, é necessário antes compreender como se pensa e se lida com a suposta dicotomia entre "tradição" e "modernidade" naquela realidade.

Ao estabelecer-se uma doença como "tradicional", presume-se que ela esteja inserida num campo específico de causas, conseqüências e procedimentos devidos para o seu trato. 
"As mulheres são más"

Sua definição é sempre precedida por um processo especulativo a respeito de um grande número de variáveis, que envolvem principalmente os sintomas e seu desenvolvimento, e é concluída com o diagnóstico obtido junto a um curandeiro que emprega o tihlolo para determinar suas causas.

Normalmente, a "doença tradicional" é aquela que tem desenvolvimento percebido como atípico, seja pelo seu prolongamento ou recorrência, seja pela rapidez com que advém a morte, seja ainda pelo conjunto de múltiplos sintomas e sinais no corpo que se articula com outros problemas não corporais (baixa produtividade das machambas e doenças e mortes entre familiares, por exemplo). Porém, a qualquer doença pode ser atribuída uma causa "tradicional" - mesmo aquelas com desenvolvimento típico e sabidamente tratáveis biomedicamente. No diagnóstico "tradicional", faz-se uma revisão das relações que o doente estabeleceu com seu ambiente social e físico, a fim de se encontrar nelas as possíveis causas de uma doença. As causas das "doenças tradicionais" tendem a ser remetidas a um quem, como atesta Alf Helgesson (1971) em seu estudo sobre os vaTsua, grupo majoritário em Homoíne. Portanto, toda "doença tradicional" tende a ser pensada como resultado de interações pessoais e da ação de outrem sobre o corpo de alguém. Por isso perguntei ao pai de José quem havia produzido aquela doença.

Mesmo num ambiente de "modernidade" disponível como encontramos na vila de Homoíne, com acesso a aparelhos estatais e recursos urbanos, a "tradição" é sempre uma causa potencial de doenças e não necessariamente abdica-se desse diagnóstico quando se tem uma doença tratada e curada pela biomedicina. Uma doença pode ser conjuntamente tratada pela biomedicina $e$ pela medicina tradicional, sem que os sujeitos percebam contradições nesse procedimento. Porém, as pessoas em Homoíne reconhecem algum tipo de especificidade das doenças $e$ tratamentos definidos como "tradicionais" ou não, mesmo nos tratamentos conjuntos, pois reconhecem a existência de campos distintos que identificam como "tradição" e "modernidade". 
Os habitantes da vila-sede referem-se constantemente ao curandeirismo, à feitiçaria, ao "poder tradicional", à família, aos antepassados, aos ritos e às "cerimônias tradicionais" como dados remetidos a um universo que denominam "tradição africana" ou "africanismo", delimitado discursivamente pelas expressões "nos tempos", "naquelas zonas" e "aquelas pessoas". Ou seja, discursivamente, os moradores de Homoíne operam emicamente num registro dicotômico que remete a "tradição" a um outro tempo (sempre remoto), um outro espaço (sempre distante) e um outro universo social (sempre diverso), construindo por oposição o campo da "modernidade" como aquele que experimentam mais claramente na vila - cuja urbanidade é percebida como mais próxima de uma vida "moderna". Constroem, assim, campos discursivos que instituem sujeitos, temporalidades e locais diversos $e$ até mesmo contraditórios entre si, estabelecendo alteridades bem demarcadas. Isso lhes permite identificar, classificar, hierarquizar, sistematizar e lidar com um conjunto múltiplo de dados objetivos e discursivos que se interpenetram de forma aleatória na prática da vida cotidiana. Dessa forma, a vila lhes fornece um espaço de "modernidade" concebível e perceptível, confortável e segura, oposta à "tradição" que se encontraria restrita ao campo ou ao mato - termos utilizados para referirem aos universos "daquelas zonas", nos quais "aquelas pessoas" ainda vivem como "nos tempos". Elabora-se, portanto, uma taxonomia binária das transformações e permanências percebidas, e é dessa forma que se observa a efetividade e funcionalidade das estratégias discursivas de construção da "tradição" e da "modernidade" na vila-sede. Essa taxonomia atualiza-se constantemente em discursos e performances ${ }^{10}$ que se apropriam de certos signos reconhecidos como "modernos" (indumentária, vocabulário, corporalidade, consumo, etc.) para estabelecerem fronteiras e rupturas com o universo do campo ou do mato.

${ }^{10}$ Emprego as noções de performance e performatividade para caracterizar que identidades e pessoas resultam de um fazer pragmático, na mesma perspectiva de Judith Butler (1990) para a análise de gênero. 
"As mulheres são más"

O campo percebido da "modernidade" está também associado ao universo do mercado e do Estado com seus aparelhos (hospitais, tribunais, escolas, repartições públicas, lojas, bancas e barracas ${ }^{11}$ ), onde performatiza-se, discursa-se e negociase através do uso de elementos consensualmente reconhecidos como pertencentes a um universo "moderno" e urbano - a vilasede é o espaço onde se reconhece que esses elementos existam de forma mais constante e sedimentada em Homoíne. A "tradição", por seu turno, está onde o Estado e seus aparelhos inexistem ou encontram-se precariamente instalados, ou ainda subordinam-se às instituições "tradicionais" - esse é o lugar do campo ou mato. Enfim, ao nível de uma taxonomia discursiva, o que se quer "moderno" em Homoíne é aquilo que remete a um universo urbano, e o que remete ao rural é o que se quer delimitar como "tradicional".

Contudo, diante de eventos críticos como a doença $e$ a morte, o que se observa é uma desconstrução dessas discursividade e performatividade ao nível pragmático, e a vida dos habitantes da vila é invadida pela "tradição" - mesmo porque eles se percebem como vulneráveis a ela, uma vez que são majoritariamente oriundos do campo ou em relação permanente com ele através de seus familiares e machambas. Tais eventos implodem as taxonomias sociais que delimitam os universos "moderno" e "tradicional", desencadeando ações que rompem com qualquer fronteira que se queira clara entre eles. Inclusive amalgamam os aparelhos da "modernidade" e da "tradição", estabelecendo continuidades - do hospital ao curandeiro e viceversa, não se constrói um percurso de rupturas, mas sim de continuidade pragmática. O que se revela, então, é a fragilidade ou mesmo irrealidade desses campos e fronteiras compostos por alteridades excludentes e contraditórias, que são bem definidos

${ }^{11}$ Banca é o termo que designa pequenas construções que abrigam atividades de comércio. Barracas são tendas cobertas que se observa nos mercados públicos e nas ruas. 
apenas ao nível do discurso. Olhar para os móveis que constituem os dramas sociais em Homoíne exige que, no mínimo, se suspeite da operacionalidade de uma análise que tome como certa e clara a separação entre "tradição" e "modernidade" nos processos sociais ligados à doença e à morte, assim como aos demais níveis do universo social e das relações interpessoais.

Nesse sentido, é mais rentável tentar entender as formas de socialidade em contextos como Homoíne a partir das lógicas, ontologias e cosmologias que as produzem, o que nos remete necessariamente ao enfrentamento de questões de feitiçaria, curandeirismo, família, parentesco e demais categorias ditas "tradicionais", que são rotinizadas e de incontestável contemporaneidade naquela realidade. É preciso levar a sério os discursos sobre as "tradições" locais, pois eles operam com sistematizações cosmológicas e ontológicas que revertem num pragmatismo que constrói mundos sociais ${ }^{12}$ particulares $e$ irredutíveis a não ser a si mesmos, impondo as forças "tradicionais" como realidade experimentada pelos sujeitos e que reverberam nas relações com os campos institucionalizados da "modernidade". Minha hipótese é que está aí a chave para se compreender universos tão complexos e refratários a análises dicotômicas como o que encontrei em Homoíne.

\section{Pessoa e risco}

Falar em ontologias é falar também em noções de pessoa. A literatura antropológica sobre a vida sócio-cultural no Sul de Moçambique demonstra a centralidade do parentesco e das formas familiares na constituição da pessoa e dos sistemas socioculturais. De Henri A. Junod a Alcinda Honwana, passando por David Webster e Brigitte Bagnol - autores com quem dialogo aqui -, temos uma série de estudos que apontam a necessidade

\footnotetext{
${ }^{12}$ Emprego a noção de construção de mundos no sentido do worldmaking de Nelson Goodman (1978).
} 
"As mulheres são más"

de compreendermos as formas de aliança e descendência para explicarmos a lógica dos sistemas sócio-culturais e das individualidades erigidas a partir deles, e que operacionalizam $e$ constroem as realidades observadas em Homoíne.

Esses autores apontam de formas diversas e em outros termos que para se pensar o sujeito no Sul de Moçambique, é necessário atentar para o fato de que naquela área operam uma ontologia e uma noção de pessoa particulares, que permanecem como fundamentos das relações desses sujeitos com o mundo, mesmo diante de transformações históricas importantes e críticas, e mesmo com a incorporação constante de novos elementos sócio-culturais. O que permanece não é um conjunto de "usos e costumes" sedimentado, nem estruturas rígidas ${ }^{13}$, mas um conjunto de princípios lógicos, cosmológicos e ontológicos presentes nas formas de aliança e descendência que fundam os sujeitos $e$ sua realidade, estruturam as relações entre vivos $e$ mortos e destes com uma certa natureza. Esses princípios são reafirmados constantemente e, em grande medida, permitem compreender a maneira como se estabelecem pragmaticamente as relações de gênero $e$ as relações com as doenças num contexto de profundas e constantes transformações.

Em Homoíne me deparei com fatos que apontam certo padrão de construção da pessoa na relação com seus pares. Grosso modo, em parte, a pessoa é definida por relações de descendência à medida que deve estar em constante relação com antepassados, madodas ${ }^{14}$, pais, irmãos, filhos e netos, que são definidos por relações agnáticas e também matrilaterais. Uma pessoa está incompleta se não é remetida a um grupo de ascendentes e se não produziu descendência. Pelo lado das alianças e da matrilateralidade, uma pessoa não está completa se

${ }^{13}$ David Webster (1976) chama atenção para a fluidez dessas estruturas entre os Chopi, que habitam área contígua à que estudei.

${ }^{14}$ Madoda é o termo empregado para se referir aos homens "grandes", em geral mais velhos, que se tornam referenciais e respeitados nas comunidades e nas famílias. 
não se casou, se não tem sograria ${ }^{15}$ (termo usado para se referir ao grupo familiar dos seus esposos ou esposas) e se não tem genros, noras e os afins que esses estabelecem. Num nível mais amplo, as alianças se estendem para formas não familiares, como a vizinhança $e$ os xarás $^{16}$ (quando estes não são homens $e$ mulheres da família de quem se herdam os nomes), além das igrejas, dos círculos de amizades mais ou menos formais e da posição e relações no mundo do trabalho. É esse conjunto de relações que define uma pessoa em Homoíne, e a construção dessa rede é o principal investimento do sujeito para a definição de sua existência social, à semelhança do que David Webster (1976) observou entre os Chopi. Minha ressalva em relação a Webster é que o sujeito que se constitui numa situação como essa não é um indivíduo weberiano, mas um sujeito mais próximo do padrão divíduo, observado por Marylin Strathern (1988) na Melanésia.

Esse conjunto de relações descreve uma trajetória de vida e de acúmulo de um capital social por parte da pessoa que, após sua morte, irá definir seu estatuto no mundo dos espíritos e o tipo de relação que haverá entre ela e os vivos. Esse capital social acumulado define o "homem grande" 17 em vida, e será transferido para sua existência como antepassado. Não é diferente para as mulheres, embora elas sejam respeitadas principalmente pela descendência que ajudaram a gerar e pelo sucesso de suas machambas, sendo indissociáveis dos "homens grandes" dos quais foram esposas, mães ou pertencentes às suas famílias - via

${ }^{15} \mathrm{~A}$ respeito da noção de sograria, também utilizada entre os indianos hindus no Sul de Moçambique, ver Jardim (2007).

${ }^{16}$ Sobre os usos do termo xará e do papel dos parentes agnáticos e matrilaterais, dos vizinhos e dos amigos formais, ver Webster (1976). Xarás são indivíduos que compartilham o mesmo nome. A troca de nomes estabelece uma forma de aliança que estabelece um xará como uma espécie de parente. O mesmo ocorre com vizinhos e amigos formais.

${ }^{17}$ Sobre a noção de "homem grande", ver Junod (2003 [1926]) e Webster (1976). 
"As mulheres são más"

de regra referidas aos esposos e seus grupos agnáticos, ou aos grupos agnáticos dos quais provêm. Nesse sentido, temos em Homoíne um processo de construção da pessoa muito semelhante àquele que os Comaroff (2001) descrevem entre os Tswana e que eles definem como um being-in-process. A pessoa é um projeto que se realiza quando esta se torna um antepassado lembrado $e$ respeitado pelos seus descendentes, tendo por função proteger seu grupo familiar e intervir quando a ordem devida é rompida por um dos seus membros ou por ação de elementos extra-familiares. Isso permite que tenha seu nome guardado pela família $e$, posteriormente, atribuído aos descendentes, o que estabelece uma forma de retorno e permanência na vida familiar e social - esse mecanismo de nominação é a outra modalidade de xará que se observa em Homoíne, envolvendo nomes tanto masculinos quanto femininos. Da mesma forma, deve ser lembrado por seus vizinhos e pela sua comunidade mais ampla como alguém que produziu alianças respeitáveis e relações alargadas, que estenderam sua influência e poder para além do núcleo de descendência. $\mathrm{O}$ nome e as terras, que são expandidas à medida que o "homem grande" expande-se pela descendência e pelas alianças, tornam-se componentes indissociáveis dessa pessoa. Quem os herda, herda também sua "grandeza" socialmente reconhecida. Os nomes são chaves que abrem determinadas portas, por assim dizer, $e$ são definidos por descendência $e$ alianças. Portanto, reconhecendo algumas transformações produzidas por incorporações históricas, o que se vê na construção da pessoa é um esquema ainda muito semelhante àquele que Henri Junod (2003) observava e descrevia na vida do indivíduo em finais do século XIX.

Essa é a raiz da persistência de um pragmatismo dito "tradicional" num ambiente de incorporações "modernas", como descrito anteriormente: dentro de uma certa "modernidade" presente em Homoíne, a pessoa ainda constrói-se na lógica de uma ontologia persistente e englobante, manipulando signos diversos para produzir socialidades nas quais possa se reconhecer 
e ser reconhecido por seus pares. Embora se observe componentes classificados como "modernos" atuando na realidade, quem a constrói é a pessoa "tradicional", recompondo sua ontologia mesmo a partir de uma mistura aparentemente promíscua de signos "tradicionais" e "modernos". Assim a realidade social reconstrói-se permanentemente pela lógica da construção da pessoa, através da manipulação de elementos "tradicionais" e "modernos", sem que isso exija a persistência de "usos e costumes" específicos.

A pessoa não se define pela materialidade e objetividade dos "usos e costumes" em si, mas pela maneira como os ordena, reordena, inventa e reinventa, recompondo nessa performatividade de elementos múltiplos uma unidade ontológica e pragmática coerente com os pressupostos e princípios que a definem, e que também definem a realidade que reconhece. Diante dessa realidade, não cabe uma análise centrada no pressuposto da dualidade, contradição e complementaridade entre "tradição" e "modernidade" pela mera presença de elementos classificados externamente como "tradicionais" e "modernos". No nível pragmático, os sujeitos não os diferenciam - exceto a posteriori, quando essa taxonomia se impõe para eles mesmos, como necessidade discursiva para delimitar campos da experiência e do conhecimento que se quer distintos. $O$ que importa, portanto, é o que se faz com esses elementos e a que eles remetem para os sujeitos que os manipulam. Assisti algumas cerimônias identificadas pelos meus sujeitos de pesquisa como "tradicionais": mhambas, lobolos, funerais e deposições de flores ${ }^{18}$. Todas elas estão perpassadas por elementos "modernos", como os lobolos observados por Brigitte Bagnol (2006). Porém, esses elementos estavam ali somente como marcadores de um certo estatuto de urbanidade dos participantes, sem que fossem vistos como anacrônicos e contraditórios em relação ao caráter

${ }^{18}$ A deposição de flores é a fase final do processo funerário, realizada oito dias após o enterro. 
"As mulheres são más"

"tradicional" que era experimentado. Reafirmam, portanto, aquilo que Bagnol indica em relação ao lobolo: o caráter dessas cerimônias é ontológico e, dessa forma, repõe e reafirma princípios de construção de mundos e pessoas calcados em fundamentos persistentes, relacionados ao parentesco e à cosmologia. Por isso, explicitam aspectos cruciais que pretendo discutir aqui.

Durante uma mhamba que assisti em julho de 2007 em Homoíne, de uma família recomposta após o massacre de $1987^{19}$, perguntei ao dono da casa se a curandeira que intermediava a consulta aos antepassados morava naquela zona. Ele, espantado, negou veementemente. Disse que jamais poderiam chamar uma curandeira que vivesse próxima à família, ou que conhecesse os familiares. Seria um grande risco colocá-la em contato com os antepassados protetores, pois ela poderia romper a proteção $e$ lançar malefícios contra a família. Isso remete a algo que percebi de forma generalizada no campo: os malefícios não vêm de longe, mas sempre de muito perto - de dentro do grupo familiar, da vizinhança $e$, de forma menos recorrente, dos demais círculos $e$ redes sociais nos quais os sujeitos estão inseridos. $\mathrm{O}$ caso da doença e morte de José explicita isso. Os campos de socialidade que oferecem maior potencial de agressão e risco são sempre aqueles que estão mais próximos dos sujeitos. É como se familiares e vizinhos fossem permanentemente inimigos potenciais, aos quais, por isso mesmo, se dirige a maioria das acusações de feitiçaria e das atitudes preventivas. E há muitas acusações de feitiçaria em Homoíne.

Durante minha pesquisa, deparei-me com um ambiente em que as pessoas temem umas às outras e expressam isso através de discursos e atitudes recíprocas. Esse temor está normalmente expresso nas falas sobre violências desencadeadas por feitiços ou por ações de bandidos - como se nomeia os criminosos,

${ }^{19}$ Em 18 de julho de 1987, a vila-sede de Homoíne foi palco do mais significativo massacre ocorrido durante a guerra civil em Moçambique. 
normalmente produtores de pequenos furtos, mas também perpetradores de agressões físicas e, eventualmente, mortes. Existem discursos sobre uma violência real ou presumida, e um clima de insegurança que resulta da percepção de uma vulnerabilidade permanente às ações de bandidos e feiticeiros que, embora distintos como categorias e processos, aparecem de forma semelhante na construção do temor e da desconfiança. $\mathrm{O}$ que une essas categorias é a noção de ambição, percebida como motor de suas ações. Porém, os discursos têm formas diferentes: quando remetem à bandidagem, as falas são objetivas, diretas $e$ explícitas; quando se fala na feitiçaria, isso é feito por meias palavras, elipses e de forma fragmentada, como rumores. Se a bandidagem coloca em risco os bens, as casas e os corpos por ações diretas, impondo medidas preventivas e punitivas também diretas e objetivas contra seus agentes, a feitiçaria coloca os mesmos elementos em risco e os amplia para a família e demais círculos de relações pessoais e sociais, mas através de ações indiretas, capilares e silenciosas, o que a torna de difícil identificação, prevenção e punição, sendo a causa referida da maior parte das "doenças tradicionais". Essa natureza de agenciamento rizomático ${ }^{20}$ torna a feitiçaria um elemento mais difuso e amplificado, menos objetivo e pontual e, por isso, mais temido que a bandidagem.

Numa comunidade pequena como a vila-sede de Homoíne, onde todos se conhecem ou podem ser encontrados através de redes sociais que se entrecruzam, torna-se muito fácil identificar os atos e autores das bandidagens, prevenir-se contra eles e puni-los pelas vias formais. Já as ações e malefícios atribuídos à feitiçaria, de caráter oculto, tendem a desencadear processos contínuos que atingem vítimas nem sempre previsíveis, sendo objeto de especulação sobre seu diagnóstico e agente responsável. Além

${ }^{20}$ Emprego a noção de rizoma de Gilles Deleuze e Félix Guattarri (1980), por entender que ela explica a forma pouco estruturada e imprevisível das ações e processos atribuídos à feitiçaria. 
"As mulheres são más"

disso, não há instância formal para punir a feitiçaria, exceto o recurso à AMETRAMO. ${ }^{21}$ Além dos curandeiros, recorre-se à expulsão do feiticeiro ou ao contra-feitiço, o que repõe o esquema de predação e contra-predação que ela envolve, criando uma espiral ascendente de insegurança e violência presumida.

Nas falas sobre a violência que ouvi em Homoíne, a feitiçaria aproxima-se mais das descrições sobre os ataques imprevisíveis dos matsangas ${ }^{22}$ (os bandidos armados da RENAMO) do que da bandidagem atual, ainda que sejam notáveis as conexões que essas falas produzem entre a guerra, a criminalidade $e$ a feitiçaria enquanto violência - os discursos sobre esses temas eram estruturalmente muito semelhantes. A indeterminação da feitiçaria, sempre inserida num campo especulativo de causas $e$ conseqüências obscuras $e$ de processos contínuos $e$ não estruturados, empresta a ela um caráter de poder e perigo muito maior que aquele reconhecido na bandidagem contemporânea $e$ muito mais próximo do atribuído aos matsangas. ${ }^{23}$ Vale notar que a feitiçaria esteve associada às representações sobre a violência durante a guerra civil. ${ }^{24}$ Ela permite dar forma e expressão a uma insegurança difusa e permanente em relação aos perigos,

${ }^{21}$ Sigla da Associação dos Médicos Tradicionais de Moçambique, entidade reconhecida pelo Estado. Observei em minha pesquisa uma preponderância de sua atuação jurídica na solução de casos reclamados como ações de feitiçaria, inclusive alguns encaminhados à AMETRAMO pelo próprio Tribunal Distrital de Homoíne. Sobre a história e as formas de atuação da AMETRAMO, ver Meneses (2004), Meneses et alii (2003) e Honwana (2002).

${ }^{22}$ Termo utilizado para se referir aos soldados da RENAMO (Resistência Nacional Moçambicana), que se opôs ao governo da FRELIMO (Frente de Libertação de Moçambique) durante a guerra civil. A raiz etimológica da palavra matsanga é o nome do primeiro líder da RENAMO, André Matsangaíssa. Referia-se também aos soldados da RENAMO como bandidos armados para qualificá-los como criminosos.

${ }^{23}$ Segundo Douglas (2002), as noções de perigo e poder estão associadas a espaços intersticiais, indeterminados e não estruturados.

${ }^{24}$ Sobre os usos da feitiçaria, do curandeirismo e das religiões durante a guerra civil, ver Geffray (1990) e Honwana (2002). 
imprevistos e imponderáveis da vida cotidiana que colocam a pessoa em risco.

Outro aspecto que causa insegurança e desencadeia falas de um perigo iminente para a desconstrução da pessoa diz respeito à gestão dos antepassados sobre a vida individual e familiar e sobre a natureza. Protetores por um lado, os antepassados são também objeto de ansiedade por parte das pessoas, uma vez que seu descontentamento resulta em punições. Rupturas nos laços de família e parentesco, desobediência a regras e tabus e desrespeito aos elementos naturais que estão sob sua guarda revertem em malefícios para os vivos. Donos da terra e dos ciclos e elementos naturais, os antepassados são também donos de certas mulheres a quem são concedidas em matrimônio - fato apontado anteriormente, também descrito e analisado por Honwana (2002) e Bagnol (2006), e que compõe as especulações em torno da doença de José. $\mathrm{O}$ acesso a esses elementos e pessoas exige sua autorização. Os usos indevidos de suas posses $e$ o não cumprimento de seus mandos resultam em punição. De protetores, muitas vezes os antepassados, em certo sentido, transformam seus descendentes em inimigos e, por conseqüência, transformam-se também em inimigos e predadores para seus descendentes.

Ainda em relação ao esquema de predação social observado em Homoíne, é notável a equivalência e mesmo indistinção que as pessoas costumam fazer entre curandeiros $e$ feiticeiros. Ao invés de integradores - como descreve Honwana (2002) -, os habitantes da vila vêem os curandeiros como potenciais desintegradores da vida social e da pessoa. Tão desintegradores quanto os feiticeiros e tanto mais freqüentemente quanto mais próximos estejam da vila - por essa perspectiva, aos olhos dos habitantes da vila, os curandeiros do mato ainda curariam e não produziriam malefícios. As falas dão conta de curandeiros que produzem malefícios, instauram intrigas entre familiares e vizinhos, escravizam seus consulentes a dívidas infindáveis e impagáveis e que são procurados para fornecerem 
"As mulheres são más"

feitiços que beneficiem seus consulentes "ambiciosos". Os curandeiros são acessíveis apenas àqueles que têm posses, pois suas consultas são caras, constituindo-se assim num fenômeno de classe em Homoíne. Os que não têm posses, além de se protegerem-se nas igrejas contra os curandeiros e seus consulentes "ambiciosos", fogem para os centros urbanos maiores, onde se sentem menos vulneráveis à "tradição" e longe dos conflitos familiares que podem desencadear feitiços. Notadamente as mulheres procuram as igrejas para se protegerem de feitiços e das acusações de serem feiticeiras.

As consultas aos curandeiros são vistas como uma forma de obtenção de benefícios para ascensão social e ganhos de capital num mercado de trabalho extremamente competitivo, dada a baixíssima oferta. ${ }^{25}$ Essa busca por benefícios tem até mesmo um verbo específico: kukhendla, em citsua - em português, o verbo é transformado no neologismo khendlar. Kukhendla tradicionalmente significa procurar poderes mágicos nos curandeiros para a obtenção de bens, força física, defesa contra inimigos e qualidades pessoais que tornem a pessoa bem vista $e$ bem posicionada socialmente. Durante a guerra civil, os soldados khendlavam para obter proteção contra armas e, atualmente, num ambiente de paz e mercado liberal, a demanda das pessoas desloca-se para obtenção de benefícios trabalhistas e materiais, $e$ o dinheiro circulante inflaciona os preços dos curandeiros. Portanto, observa-se uma constante atualização histórica desse fenômeno.

A efetivação e continuidade da kukhendla exige sacrifícios de animais e mortes de pessoas como contrapartida - pessoas que, em geral, pertencem à família. Os espíritos dos mortos são dados aos curandeiros que, com eles, aumentam seus próprios poderes. Kukhendla é um dos fenômenos associados à noção corrente de feitiço que encontrei em Homoíne, e o principal fator

${ }^{25}$ A respeito das relações entre feitiçaria, curandeirismo e mercado, ver Passador, $2009 b$. 
para a construção da equivalência entre curandeirismo e feitiçaria expressa nas falas. Ademais, é o princípio explicativo de várias acusações endereçadas ao pai de José. A demanda atual por curandeiros na vila deslocou-se da cura para a obtenção de benefícios pessoais ligados às exigências de uma vida "moderna". Meneses (2004) aponta que as aflições da "modernidade", referidas ao mercado, potencializam a busca por benefícios nos curandeiros. Em Homoíne, as consequências dessa busca se explicitava nas falas dos sujeitos: o benefício de uns exige o malefício para outrem, o que resulta em insegurança generalizada e desconfiança em relação àqueles que obtêm sucesso. Remete-se o curandeirismo, portanto, ao campo da discursividade sobre a violência contra a pessoa. Se a busca pelo bem-estar e sucesso resulta do próprio processo de construção da pessoa, esse processo se dá em constante experiência de riscos e perigos potenciais, envolvendo disputas e negociações permanentes com elementos que podem impedir sua realização.

Nos campos definidos pela descendência e pelas alianças matrimoniais, há recorrência de acusações de desconstrução da pessoa pelo uso de feitiços, como exemplifica o caso de José. Majoritariamente, acusam-se as mulheres de perpetrarem tensões, doenças e mortes entre parentes por aliança e descendência. Esse ponto de articulação entre construção da pessoa, ação das mulheres no seio da família e produção de doenças serão discutidos mais adiante.

Os fenômenos relativos à construção da pessoa e aos riscos de sua desconstrução podem ser interpretados a partir de uma matriz comum, que permite compreendê-los pela ótica de uma análise empregada contemporaneamente nos estudos de grupos ameríndios. ${ }^{26}$ Tudo indica que o sistema social em questão tem por fundamento o conflito que certos mecanismos sociais procuram pacificar. Nesse sentido, os conflitos que a feitiçaria, a bandidagem, os matsangas, o curandeirismo e os antepassados

${ }^{26}$ Em especial as obras de Viveiros de Castro (2002) e Fausto (2001). 
"As mulheres são más"

desencadeiam ou representam não são rupturas anômicas de uma ordem social funcional e harmônica por princípio. O conflito é uma possibilidade permanente da própria ordem social. Esta se constrói a partir do reconhecimento do conflito e da predação como fundamentos permanentes e virtuais das relações com inimigos primordiais, cuja origem remete às guerras pré-coloniais de ocupação da área (cf. Passador, 2009b), o que exige mecanismos e processos de pacificação constante através de socialidades que produzem pessoas e redes sociais. Nesse caso, é possível repensar o sistema de parentesco da área investigada $e$ as alianças que se estendem para além dele, assumindo que operam como uma matriz de pacificação permanente e sistemática de inimigos potenciais inseridos dentro dos campos de relações que constituem a pessoa. As redes sociais formam campos de relações em permanente risco de desconstrução dos processos de pacificação que as constituiu. $O$ inimigo não é um elemento construído por um conflito pontual que rompe ordens solidárias prévias, mas surge da desconstrução das relações que $\mathrm{o}$ pacificaram, ao ser introduzido em campos de socialidades sob um regime de poder hierárquico. Portanto, a construção social do inimigo se dá com a sua reposição ontológica, através da desconstrução de um campo de agenciamentos e socialidades que buscam pacificá-lo. Isso explica porque o inimigo é sempre percebido como muito próximo e porque as acusações de feitiçaria são normalmente endereçadas aos familiares e vizinhos principalmente às mulheres. O exemplo de José e as especulações formuladas em torno de sua doença e morte podem ser entendidos nos termos dessa proposição.

De maneira mais objetiva, proponho que se pensem as alianças matrimoniais na área como mecanismos de incorporação e pacificação de inimigos potenciais a núcleos de descendência já pacificados pela hierarquia agnática. Num sistema de descendência agnática, tem-se que sua perpetuação exige a incorporação de mulheres $e$ afins através das alianças matrimoniais. Mulheres $e$ afins vem de fora, de outro grupo de 
descendência, como estrangeiros ou vientes ${ }^{27}$ - termos usados em Homoíne, de forma indistinta, quando se quer referir a sujeitos que venham de fora de um determinado universo tomado como o "dentro". Os vientes são sempre objeto de suspeita e temor, pois são, por princípio, inimigos potenciais que exigem pacificação. São a esses elementos originalmente "de fora", mulheres e afins incorporados por aliança, que se voltam os principais temores de agressão e desconstrução da pessoa.

Por outro lado, as alianças e pacificações operadas por ascendentes podem ser rompidas por seus descendentes, rompendo com os investimentos da pessoa que inaugurou um núcleo de descendência. Os ascendentes, por sua vez, em função de sua posição hierárquica geracional, podem punir seus descendentes insubordinados, assim como submetê-los aos seus interesses e ambições - que é o caso das relações entre José e seu pai, e o caso mais geral das punições dos antepassados. Assim, tanto são inimigos potenciais as mulheres e os afins, quanto os ascendentes e os descendentes. Por isso tem-se uma ambiguidade constante nas relações de parentesco: se a pessoa se constrói numa rede de relações de aliança e descendência, há também um grande potencial de predação e desconstrução da pessoa pelas mesmas vias.

Num esquema de alianças ampliadas para campos não familiares, como a vizinhança, observa-se a mesma lógica: formando um agregado por alianças, os vizinhos são parceiros, mas também inimigos potenciais porque vientes incorporados $e$ pacificados de fora para dentro. A versão que tomava o vizinho como aquele que produziu a doença de José se baseava nessa lógica.

Disso resulta uma matriz social que opera por trocas recíprocas e solidárias, mas que dependem de um poder

${ }^{27}$ A raiz etimológica do termo viente é o verbo vir, e se refere àquele que vem de outro lugar. Opera como marcador de alteridade em relação à origem e/ou procedência de um sujeito. 
"As mulheres são más"

hierárquico para serem preservadas, posto que, no fundamento, seus agentes são inimigos pacificados que podem retomar seu estatuto predatório original. Assim se constrói e se desconstrói a pessoa, e é assim que se pode pensar a saúde, a doença e a morte por feitiçaria nos termos do sistema "tradicional", como no caso de José.

\section{Gênero, poder e doença}

Se essa interpretação está correta, temos aí uma abertura para compreender as relações de gênero e geração que perpassam tal matriz e que revertem em conflitos recorrentes associados ao feminino $e$ aos mais velhos - em especial às mulheres mais velhas. Em Homoíne, temem-se as mulheres por atribuir-lhes um poder de causar rupturas, produzir agressões e desintegrar campos de socialidades. São, portanto, inimigas em potencial submetidas a constantes procedimentos de prevenção de males $e$ de pacificações hierárquicas por parte dos homens. Vindas de fora no esquema das alianças matrimoniais, permanecem como vientes $e$ inimigas em potencial, assim como seu grupo familiar de origem os afins. Portanto, o poder ao qual estão submetidas nessa matriz é operado como um contra-poder masculino que procura anular os males que elas podem desencadear no universo familiar. $\mathrm{O}$ que é necessário do ponto de vista da construção da pessoa masculina, pois sem mulheres não se realizam a descendência, as alianças e a masculinidade. Mas não só isso.

Reconhece-se nas mulheres um poder de natureza ambígua e específica. Sendo elas as curandeiras e as feiticeiras, são elas que mantêm relações especiais com o mundo dos espíritos e tem a capacidade de fazê-lo atuar sobre o mundo dos vivos. Quando são curandeiras, permitem os agenciamentos dos espíritos sobre a vida social, o que as torna cruciais para a integração $e$ manutenção de uma ordem desejável. Quando são mães e esposas, permitem a realização da descendência e das alianças. Portanto, elas são a possibilidade da pessoa. Mas também são elas 
que agridem parentes $e$ vizinhos com feitiços $e$ instauram intrigas $e$ conflitos como curandeiras, desconstruindo pessoas. Esse poder ambíguo resulta de sua própria posição nos esquemas locais de descendência e alianças, pois é através delas e nelas que esses mecanismos se realizam.

Strathern (1988) propôs que as relações de aliança ideais entre homens, que ela denomina de relações same-sex, só são possíveis através das relações de alianças reais entre homens $e$ mulheres, ou relações cross-sex. Assim, a relação de afinidade virtual e potencial entre grupos familiares encabeçados por homens só pode se realizar concretamente através da aliança matrimonial entre homens e mulheres desses grupos. Portanto, às mulheres cabe esse potencial de instaurar e selar alianças.

No plano dos espíritos e do curandeirismo observa-se o mesmo fenômeno. Honwana afirma que a categoria nyamussoro ${ }^{28}$ é original dos vaNdau, da região Centro, e entre eles era uma categoria exclusivamente feminina, tendo sido reelaborada no Sul em função das guerras pré-coloniais. Se atentarmos para a descrição que a autora faz do surgimento dessa categoria no Sul de Moçambique, veremos que ela só é possível de ter se constituído pelas mulheres e por seu papel na descendência e na aliança: a incorporação de espíritos masculinos vaNguni e vaNdau a grupos Tsonga se deu por alianças cross-sex entre estes espíritos $e$ mulheres concedidas a eles como esposas (as nsati wa suikwembo), afinizando-os e transmitindo-os por descendência às gerações posteriores - o que permitiu aos homens tornarem-se vanyamussoro posteriormente, pela transmissão e possessão de

\footnotetext{
${ }^{28}$ Nyamussoro (pl. vanyamussoro), segundo Honwana (2002), é a categoria mais poderosa de práticos no sistema médico tradicional do Sul de Moçambique. Um nyamussoro opera os espíritos linhageiros tsonga (tinguluve, sing. nguluve) juntamente com os espíritos nguni (pl. vanguni) e ndau (pl. vandau), originários respectivamente das áreas zulu e do Centro de Moçambique. Para a autora, essa categoria se construiu no Sul em decorrência da invasão dos vaNguni, que subordinaram os Tsonga e os vaNdau e produziram alianças matrimoniais $e$ espirituais hierárquicas entre esses três grupos.
} 
"As mulheres são más"

espíritos de suas antepassadas vanyamussoro. Portanto, o poder de cura é garantido por um poder de instaurar alianças matrimoniais, incorporando espíritos afinizados a um grupo de descendência, que é um poder feminino e que torna a nyamussoro uma categoria feminina por definição. Essa incorporação se dá por processos de pacificação, posto que antes de se tornarem espíritos de cura, eram espíritos guerreiros $e$ vingativos que vulnerabilizavam um grupo de descendência agnática. Assim, temos o paralelo entre aliança e pacificação e o campo familiar como um campo definido e produzido por estratégias de pacificação de inimigos potenciais, de fora para dentro, só possíveis de serem realizadas através das mulheres nas relações cross-sex.

Isso aponta, novamente, para a ambigüidade da situação feminina no Sul de Moçambique: integradoras e pacificadoras, as mulheres permanecem como vientes incorporadas $e$ pacificadas por aliança matrimonial para permitir a descendência dentro de um grupo ao qual não pertencem originalmente. Por um lado, intermedeiam as forças masculinas espirituais e de reprodução que tornam possível a existência da pessoa pelas vias da descendência $e$ das alianças. Por outro, permanecem inimigas em potencial que podem romper o contrato de paz que a aliança estabelece. Essa situação lhes empresta o poder reconhecido e temido. $O$ poder masculino só se torna efetivo através do poder feminino, posto que este garante a agência masculina no campo social e espiritual. Porém, o poder feminino também pode produzir rupturas $e$ conflitos que impedem a manutenção de uma ordem regida pelos elementos masculinos. É a esse tipo de poder ontológico e feminino que as acusações de feitiçaria direcionadas às mulheres procuram dar forma $e$ inteligibilidade no universo social observado, e que constrói os temores em relação a elas e às doenças que podem produzir.

São muitos os casos de acusação de feitiços atribuídos a mulheres em Homoíne. Entre tantos, há aqueles que apontam para feitiços perpetrados pelas sogras contra suas noras, o que 
indica os cortes de gênero e geração que operam para delimitar as categorias mais predadoras - e sua vulnerabilidade às acusações. O dado objetivo dessa situação era a existência de um grupo de aproximadamente trinta idosas abrigadas na missão católica próxima à vila, conhecidas entre a população local como "as velhas da missão". Segundo os missionários que as abrigavam, as "velhas" foram expulsas de suas casas pelos próprios filhos, após terem sido acusadas de feitiçaria por suas noras. As noras as acusavam de serem responsáveis por sua infecundidade, de causarem as doenças e mortes de seus bebês ou ainda de provocarem quebras de produção nas suas machambas. Ou seja, as acusações incidem sobre a impossibilidade das noras realizarem a descendência e a subsistência de seus maridos $e$, assim, não cumprirem o contrato da aliança firmado no lobolo.

Essa tensão entre noras e sogras parece ser um dado estrutural: se as noras não produzem filhos e descendência, tornam-se mulheres fracassadas e pessoas incompletas que, por conseguinte, também não permitem a completude do marido como pessoa masculina. A mesma lógica se aplica às machambas: se as noras não garantem a subsistência do núcleo familiar, tornam-se mulheres fracassadas e incompletas. Os fracassos das noras normalmente revertem em rompimento do casamento, devolução delas às suas famílias de origem e retorno dos bens negociados no lobolo. As sogras, por sua vez, reiteram sua pertença ao grupo ao qual foram incorporadas por aliança reafirmando sua ascendência sobre os filhos. Dividindo o espaço doméstico com as noras, no esquema geral de residência virilocal $e$ preferencialmente patrilocal, submetem essas a uma relação hierárquica de poder. As tensões entre ambas são notórias e sua raiz parece ser a necessidade constante de as mulheres reafirmarem sua pertença a um grupo agnático ao qual foram incorporadas por aliança, $e$ ao qual só permanecem legitimamente ligadas se garantirem sua continuidade pela descendência $e$ subsistência - filhos e comida são os bens primordiais que cabe às mulheres produzirem. Desordens na descendência $e$ na 
"As mulheres são más"

subsistência as colocam como principais suspeitas de serem suas perpetradoras.

Ainda dentro do circuito de acusações entre mulheres, são notáveis as acusações de que há mulheres que matam os filhos de outras através de feitiços - muito comuns nos núcleos poligínicos, mas também entre vizinhas e parentas. Uma das maneiras de atingir uma mulher é matar seus filhos, visto que ela se constrói socialmente pela geração da descendência. Também as "velhas da missão" viviam em permanente conflito entre si, acusando-se mutuamente de lançarem feitiços umas sobre as outras. É um ciclo de acusações entre mulheres que parece infindável, transformando supostas algozes em vítimas de fato, e de novo em algozes presumidas.

Outro dado que associa as mulheres a malefícios dentro do circuito da descendência e das alianças é a acusação, também comum, de feitiços de esposas contra seus maridos, para usufruto das posses familiares associadas a ele. Toda viúva sabe que será suspeita de ter provocado a morte de seu marido. $\mathrm{O}$ fundamento desse tipo de acusação é que elas, movidas pela ambição, se aproveitariam da influência sobre seus filhos para, num esquema de sucessão adélfica, usufruírem a herança que cabe a eles com a morte do pai. A feitiçaria aparece como possibilidade de dar forma $e$ inteligibilidade às causas dos problemas ligados à predação dentro do núcleo familiar, problemas normalmente atribuídos às mulheres incorporadas por aliança $e$ afinidade.

Por fim, acredita-se que ao envelhecerem e perderem a fecundidade e a produtividade nas machambas, as mulheres tornam-se feiticeiras para garantirem benefícios e subsistência, o que faz os maridos temerem suas esposas quando estas envelhecem. Mulheres idosas e solitárias são sempre muito temidas $e$ acusadas de serem feiticeiras, pois a elas restaria a ambição e a predação como formas de existência.

As mulheres são sempre vistas como potencialmente más: através de supostos malefícios voluntários perpetrados pela feitiçaria, colocam em risco homens e mulheres por colocarem em 
risco sua integridade como pessoas, por isso são temidas e objeto de desconfiança permanente. Mais do que funcional ou estrutural, esse dado de reconhecimento de um mal inerente às mulheres em especial as mais velhas, mas não somente - assume um caráter ontológico, pois não se restringe à posição das mulheres dentro de um sistema de parentesco. Amplia-se para uma condição de potencial impureza e perigo do feminino. $\mathrm{O}$ contato com o feminino e seu poder ambíguo envolve riscos presumidos que apontam para a desconstrução da pessoa, ao mesmo tempo em que é a possibilidade de sua construção e persistência. Por terem esse poder reconhecido, as mulheres acabam sendo subordinadas a um contra-poder masculino legitimado pelas instâncias da família e do parentesco, o que permite mantê-las pacificadas para a produção da pessoa e da matriz social que a institui. Elas são objeto de violência efetiva por serem perpetradoras de uma violência presumida, num sistema erigido em torno do pressuposto de um conflito permanente e potencial, que coloca os inimigos muito próximos de suas vítimas.

As conseqüências dessa situação rebatem para o campo das doenças, como já visto. Nesse contexto, as doenças têm o potencial de assumirem o caráter de sintomas do contato com determinadas categorias de pessoas marcadas por gênero, ou da ação voluntária dessas, sendo tomadas muitas vezes para além de meros eventos fisiológicos a serem tratados pela biomedicina constituem a categoria de "doença tradicional". Portanto, as doenças oferecem experiências concretas e críticas que permitem articular, num nível pragmático, os princípios ontológicos que operam na construção da pessoa e dos gêneros.

Por exemplo, num ambiente de epidemia pelo HIV/Aids com altas taxas de prevalência e mortes, como é o caso do Sul de Moçambique, as experiências "tradicionais" com as doenças acabam por definir relações com a sua prevenção e tratamento (cf. Passador, 2009a). Ilustrativa é a associação entre aids e xivenze que encontrei em algumas falas dos sujeitos de minha pesquisa. $\mathrm{O}$ que possibilita isso são as concepções de doença elaboradas em torno 
"As mulheres são más"

de preceitos cosmológicos e conflitos ontológicos que definem pessoas, corpos, natureza, gênero, sexualidade e toda uma sorte de experiências pragmáticas a partir delas, redefinindo a experiência com o HIV/Aids.

O que se observa, portanto, é uma constante elaboração das experiências com as doenças nos termos em que se constrói a noção de pessoa $e$ as relações de gênero, incorporadas pragmaticamente à lógica de uma ontologia persistente $e$ "tradicional". Dentro desse universo da "tradição", as mulheres são sempre problematizadas e patologizadas de maneiras específicas, o que concorre para estigmatizá-las como poderosas "putas" e feiticeiras "más", como atesta o pai de José.

\section{Referências bibliográficas}

BAGNOL, Brigitte. Gender, Self, Multiple Identities, Violence and Magical Interpretations in Lovolo Practices in Southern Mozambique. Thesis for Ph.D. Degree in Social Anthropology. Department of Social Anthropology, University of Cape Town, 2006.

BUTLER, Judith. Gender Trouble: Feminism and the Subversion of Identity. New York, London, Routledge, 1990.

COMAROFF, John L. \& COMAROFF, Jean. On Personhood: an Anthropological Perspective from Africa. Social Identities, 7(2), 2001, pp.267-283.

Deleuze, Gilles \& GuATTARI, Félix. Mille Plateaux: Capitalisme et Schizophrenie. Paris, Editions de Minuit, 1980.

Douglas, Mary. Powers and Dangers. In: Purity and Danger: An analysis of the Concepts of Pollution and Taboo. London, Routledge, 2002 [1966], pp.117-140.

FAUSTO, Carlos. Inimigos fiéis: história, guerra e xamanismo na Amazônia. São Paulo, EDUSP, 2001.

GEFFRAY, Christian. La cause des armes au Mozambique: anthropologie d'une guerre civile. Paris/Nairobi, Karthala/ CREDU, 1990.

GoOdMAn, Nelson. Ways of Worldmaking. Indianapolis, Hackett, 1978. 
Helgesson, Alf. The Tswa Response to Christianity. Dissertation for Master Degree, Faculty of Arts, University of Witwatersrand, Johannesburg, 1971.

HONWANA, Alcinda Manuel. Espíritos vivos, tradições modernas: Possessão de espíritos e reintegração social pós-guerra no Sul de Moçambique. Maputo, Promédia, 2002.

JARDIM, Marta. De sogra para nora para sogra: Redes de comércio e de família em Moçambique. Cadernos Pagu (29), Campinas-SP, Núcleo de Estudos de Gênero - Pagu/Unicamp, 2007, pp.139-170.

JunOD, Henri A. The Life of a South African Tribe. vols. I and II. Montana, Kessinger Publishing, 2003 [1926].

MENESES, Maria Paula. "Quando não há problemas, estamos de boa saúde, sem azar nem nada": para uma concepção emancipatória da saúde e das medicinas. In: SANTOS, Boaventura de Sousa \& CRUZ E SILVA, Teresa. Moçambique e a reinvenção da emancipação social. Maputo, Centro de Formação Jurídica e Judiciária, 2004, pp.77-110.

; FUMO, Joaquim; MBILANA, Guilherme \& GOMES, Conceição. As autoridades tradicionais no contexto do pluralismo jurídico. In: SANTOS, Boaventura de Sousa \& TRINDADE, João Carlos. (eds.) Conflito e transformação social: Uma paisagem das justiças em Moçambique, $1^{\circ}$ Volume. Porto, Edições Afrontamento, 2003, pp.341-425.

PASSADOR, Luiz Henrique. "Tradition", Person, Gender and STD/HIV/AIDS in Southern Mozambique. Cadernos de Saúde Pública, 25(3), 2009a, pp.687-693.

. "Eating Alone" or When Modernity Feeds Tradition: Money and Magic in Southern Mozambique. VIBRANT, 5(2), 2009b, pp.100129 [http://www.vibrant.org.br].

. \& THOMAZ, Omar Ribeiro. Raça, sexualidade e doença em Moçambique. Revista Estudos Feministas, 14(1), 2006, pp.263-286.

STRATHERN, Marylin. The Gender of the Gift: Problems with Women and Problems with Society in Melanesia. Berkeley, University of California, 1988. 
"As mulheres são más"

VIVEIROS DE CASTRO, Eduardo. A inconstância da alma selvagem - $e$ outros ensaios de antropologia. São Paulo, Cossac \& Naify, 2002.

WeBSTER, David J. Agnation, Alternative Structures, and the Individual in Chopi Society. Dissertation for Doctor Degree of Philosophy, Faculty of Arts, Rhodes University, Grahamstown, 1976. 